\title{
EDUCAÇÃO DO CAMPO: ANÁLISE DAS REIVINDICAÇÕES DOS TRABALHADORES DO CAMPO E DAS PROPOSTAS DOS GOVERNOS DE LUIZ INÁCIO LULA DA SILVA E DILMA ROUSSEFF.
}

\section{La Educación en el Campo: Análisis de las Reclamaciones de los Trabajadores do Campo Y de las Propuestas los Gobiernos Luiz Inácio Lula da Silva y Rousseff}

\author{
Rubneuza Leandro de Souzai \\ Militante e coordenadora do setor de Educação do Movimento Sem Terra no estado de Pernambuco \\ rubneuza.mst@hotmail.com
}

Artigo recebido em 14/11/2013 e aceito para publicação em 21/12/2013

DOI: 10.12957/tamoios.2013.8176

RESUMO

Refletiremos neste artigo acerca de como a política pública de Educação do Campo, fruto de muitas lutas e construção coletiva, vem sofrendo retrocessos justamente por parte de governos do Partido dos Trabalhadores. Diante dessa questão, fez-se uma análise dos governos petista de Luiz Inácio Lula da Silva (2003 - 2010) e Dilma Rousseff (2011-). Na análise dessa trajetória de dezesseis anos percebemos que a luta pela Educação do Campo sofreu retrocessos de duas naturezas: a) deslocamento de lugar da Educação do Campo que paulatinamente vem se deslocando das organizações de luta pela terra para comitês, fóruns e universidades e b) pela institucionalização da política, que afastou deliberadamente as organizações dos trabalhadores de sua condução. No correspondente à construção da política pública da Educação do Campo percebe-se que mesmo um Estado nas mãos de um partido considerado dos trabalhadores não tem sido suficiente para implementação de políticas coerentes com as reivindicações dos movimentos sociais do campo. Os resultados indicam três momentos que corresponderam à década dos governos Petistas, os quais caracterizamos como: Esperança acesa (20 03 a 2007); aceno para esquerda e virada à direita (2008 a 2010) e ceder para incorporar (2010 aos dias atuais).

Palavras-chave: Estado; Movimento Social Popular do Campo; Política Pública; Educação do Campo.

RESÚMEN Reflexionaremos en este artículo como la política de Educación del Campo, fruto de muchas luchas y construcción colectiva, viene sufriendo retrocesos justamente por parte de gobiernos de quien se esperaba que la efectivizase. Ante a esta cuestión, se hace un análisis riguroso de los gobiernos del Partido de los Trabajadores de Luiz Inácio Lula da Silva y Dilma Rousseff, articulada a la construcción de proposiciones superadoras en la lucha de los movimientos sociales populares del campo. En lo que corresponde a la construcción de la política pública de educación, se constató que un estado en manos de un partido considerado de los trabajadores no fue suficiente para la implementación de políticas coherentes de las reinvicaciones de los movimientos del campo. En el análisis realizado de esta trayectoria de dieciséis años, percibimos que la lucha por la Educación de Campo sufrió retrocesos de dos tipos, uno por el traslado del lugar de la Educación del Campo que, paulatinamente, se fue apartando de las organizaciones de lucha por la tierra a comités, fórum e centros educativos, y la segunda es en cuanto a institucionalización de la política, que se configuró más como una reedición de la educación rural retirándose de la participación de las organizaciones de los trabajadores en su conducción. . Los resultados indican tres momentos que correspondieron a décadas de los gobiernos del PT, los cuales caracterizamos como: Esperanza encendida (2003-2007), Señalizar a la izquierda y doblar hacia la derecha (2008 a 2010) y Ceder para cooptar (2010 al presente).

Palavras claves: Estado; Movimientos Sociales Populares del Campo; Política Pública; Educación del Campo. 


\section{INTRODUÇÃO}

$\mathrm{Na}$ realização desse artigoii buscou-se compreender os limites e possibilidades do processo de construção de políticas públicas de Educação do Campo no marco do Estado burguês tomando como base a análise da Educação do Campo nos governos de Luiz Inácio Lula da Silva (2003 a 2010) e Dilma Rousseff (2011-) como expressão das contradições presentes na Política Educacional dos governos petistas frente às reivindicações dos trabalhadores que lutam pela terra no campo brasileiro.

Esta pesquisa buscou compreender por que a política pública de Educação do Campo, fruto de muitas lutas, conquistas e construções coletivas, vem sofrendo retrocessos justamente por parte dos governos dos quais se esperava que as promovessem. Essa compreensão passa por uma análise que exige entender o papel que o Estado cumpre em uma determinada sociedade, seu caráter classista, em que, mesmo que se alterem os governos, mantém-se a política em defesa de uma classe ou fração de classe hegemônica. De igual forma, pretende compreender o papel que os movimentos sociais populares do campo têm desempenhado na construção das políticas públicas de Educação do Campo.

A pesquisa analisou esse recorte a partir de referências teóricas que ajudam a compreender as leis que regem o pensamento científico e permitem estabelecer nexos e relações entre o singular, o particular e o geral, ou seja, compreender o programa Saberes da Terra dentro das Políticas de Educação na relação Capital e Trabalho.

Compreendendo que o campo é diverso e incorpora em seu espaço os ribeirinhos, caiçaras, assentados, sem-terra, indígenas, quilombolas, extrativistas, entre outros, cada qual com suas formas de luta, e que também há uma quantidade significativa de movimentos de luta pela terra, este trabalho foi elaborada sob o prisma de um movimento em particular: o Movimento dos Trabalhadores Rurais Sem Terra - MST. Assim tomaremos como ponto de partida dessa caminhada, que gerou o programa em estudo, o I Encontro Nacional dos Educadores e Educadoras da Reforma Agrária- I ENERA, realizado pelo MST em Brasília, em 1997. A terminologia Movimentos Sociais Populares do Campo será utilizada para demarcar território desde o pólo do trabalhador, haja vista que as organizações vinculadas ao capital têm disputado a Educação do Campo, a exemplo da Confederação Nacional da Agricultura - CNA.

Para tanto realizamos a revisão bibliográfica e documental para compreender as relações entre Estado e movimentos sociais na construção da política pública. Foi utilizada também pesquisa documental - Projeto Saberes da Terra, Resolução No 48/2012 do MEC, PRONACAMPO; Nota Técnica sobre o Projovem Campo - Saberes da Terra e Escola Ativa; os cadernos e boletins da Educação do MST.

Primeiro procuraremos entender a relação dialética entre Estado, Educação e Movimento Social Popular do Campo, bem como, compreender como estas relações estão configuradas nos governos de Luiz Inácio Lula da Silva e Dilma Rousseff, nas relações entre Estado e Movimento de luta pela terra com a questão da reforma agrária e o direito dos camponeses à educação de qualidade. Em um segundo momento traremos a experiência educacional de um movimento em particular, o MST, para exemplificar a construção de uma outra educação possível. Finalizaremos tratando da trajetória histórica da construção da política pública de Educação do Campo, seus avanços e recuos buscando estabelecer uma análise crítica de como vem se configurando a condução dessa política nesses governos. 


\title{
AS RELAÇÕES ENTRE ESTADO, EDUCAÇÃO E MOVIMENTO SOCIAIS POPULARES DO CAMPO, NO MODO DE PRODUÇÃO CAPITALISTA - O QUE DETERMINA A POLÍTICA EDUCACIONAL PARA O CAMPO?
}

\begin{abstract}
Aê minha veia, deixa a cenoura aqui com a barriga vazia não consigo dormir e com o bucho mais cheio comecei a pensar que eu me organizando posso desorganizar e eu desorganizando posso me organizar.
\end{abstract}

(Chico Science)

A tríade aqui trabalhada, embora seus elementos apresentem independência entre si, são questões que se confrontam e se relacionam no processo da luta de classe. A relação entre Estado e Movimentos Sociais Populares do Campo dá-se de forma contraditória, pois, ao mesmo tempo em que os movimentos lutam pelo direito à educação, esse se materializa na relação com o Estado, como gestor de políticas públicas. Nesse contexto se apreende a origem contestadora das condições educacionais para a população do campo, emergidas das contradições históricas sobre a função do Estado capitalista. Nas palavras de Fernando e Martins (2009, p. 4): “A questão do Estado e das políticas sociais pode ser abordada na perspectiva das relações contraditórias imperativas desse Estado, como também, a partir das relações de força presentes na produção dessas políticas".

A epígrafe da música do Chico Science que abre esta temática nos remete a pensar esta tríade de forma dialética, partindo da idéia de que o Movimento Social, na sua essência, é educativo, pois coloca as pessoas em movimento, e no enfrentamento da luta direta aprendem a se organizar, a tomar a palavra, a transformar sua realidade imediata. E ao fazê-lo se refazem numa relação de superação e incorporação, dando um salto de qualidade nas suas ações. A epígrafe aqui citada traz duas questões importantes para análise. A primeira é que, se as condições básicas de existência forem sanadas, temos a possibilidade de alargar o olhar sobre a realidade, na medida em que o sujeito alimenta não só o corpo, mas a consciência: "Aê minha veia, deixa a cenoura aqui com a barriga vazia não consigo dormir e com o bucho mais cheio comecei a pensar". Para Marx e Engels (2009, p.40-41) isso é a produção da vida imediata natural na qual todo ser humano tem a necessidade de comer, beber, vestir e ter um teto, antes de fazer ciência e política. Isso faz parte da lei da natureza humana.

Para Taffarel, essa lei diz respeito a como nos tornamos seres humanos e constituímos ao longo da história, os modos de produção da vida, que vai desde os modos comunais primitivos até o modo de produção capitalista. Diz respeito também à necessidade histórica que os seres humanos têm de produzir e reproduzir suas condições de existência, sem as quais não se manteriam em pé. Portanto, diz Taffarel: "isto se dá pelo intercâmbio com a natureza, transformando-a e sendo por ela transformado, pelo trabalho humano, construindo-se assim a cultura" (TAFARELL, 2011, p.4),

Sob a égide do capitalismo, o trabalho é subsumido pelo capital, transformando o trabalhador em um ser alienado, que ao vender sua força de trabalho perde seu poder sobre ela, 
conferindo ao comprador utilizá-la da forma que o convier, visto que as determinações essenciais da sociedade capitalista decorrem de sua natureza mercantil.

O trabalho em Marx é ao mesmo tempo alienação e hominização. Desta forma que se coloca a luta para superar o trabalho alienado. A constituição da subjetividade humana se dá pela via do trabalho e da atividade, que diferencia o ser humano dos animais. É pelo trabalho e pela consciência que os seres humanos modificam o mundo objetivo e o subjetivo. Essa questão remete pensar o trabalho e suas formas de organização historicamente produzidas.

...Sabemos que não tem sido esta a compreensão do trabalho até o presente no interior das relações sociais vigentes, em que uma classe social dominante explora o trabalho das demais. Mesmo assim, Marx vai nos mostrar que no processo histórico foram sendo suplantadas formas de exploração do trabalho. O capitalismo, por exemplo, para se firmar, teve de suplantar as relações de trabalho escravo e servis. No entanto, como se gerou uma sociedade de classes e de exploração, a tarefa crítica, agora, é superar as relações de trabalho sob o próprio capitalismo. (FRIGOTTO e CIAVATTA, 2012, p.749)

Retomando a música de Science, ela nos faz pensar, que resolvidas as necessidades básicas da vida, abrem-se possibilidades de se fazer política e perceber as contradições da realidade, vendo-a em movimento. Mas essa possibilidade só se concretizará se as condições objetivas estiverem concretamente dadas. Será necessário que os desorganizados, busquem criar espaços de organização como, por exemplo, os movimentos sociais.

Os Movimentos Sociais Populares expressam sintomas de sociedades injustas e desiguais. Ao mesmo tempo em que tornam públicas as desigualdades, já trazem imbuídos em si elementos de uma nova ordem social. Desta forma, o Movimento Social que projeta a educação necessita dela para qualificar e avançar a luta, num movimento permanente da práxis social. Colocando como possibilidade a elevação da consciência ingênua para a consciência organizativa. Para Bogo (2011, p.22):

A maneira de ver a realidade e a capacidade de compreendê-la é que elevará o conteúdo dos níveis de consciência inferior à superior. $\mathrm{O}$ nível inferior trata-se de estar em um grau mais simplificado de compreensão da realidade, advinda de convivências individuais, em que a particularidade não se generaliza e as formas não se interligam entre si. $O$ nível superior abrange as particularidades que são superadas pela visão mais ampla e estabelecem relações universais.

Aqui se encontra o papel que a educação deveria cumprir em uma sociedade: possibilitar que os trabalhadores elevem seu nível de compreensão do real para se chegar ao concreto pensado. Superar o nível do senso comum e chegar ao bom senso. Saviani (2009, p.2), nos diz que o senso comum é intrínseco à mentalidade popular. Em contrapartida, diz ele: "as características da consciência filosófica constituem expressão de hegemonia". Desta forma, a 
classe dominante busca através de seus aparelhos privados de hegemonia, difundir nos dominados seus valores, crenças e interesses como se fossem deles, mantendo dessa forma sua hegemonia. Ainda para Saviani:

Numa formação social como a nossa, marcada pelo antagonismo de classe, as relações entre senso comum e filosofia se travam na forma de luta - a luta hegemônica. Luta hegemônica significa precisamente: processo de desarticulação-rearticulação, isto é, trata-se de desarticular dos interesses dominantes aqueles elementos que estão articulados em torno deles, mas não são inerentes à ideologia dominante e articulá-los em torno dos interesses populares, dando-lhes a consistência, a coesão e a coerência de uma concepção de mundo elaborada, vale dizer, de uma filosofia. (ibidem).

Se retomarmos as "Raízes do Brasil" (HOLANDA, 1995) não fica difícil compreender por que o Brasil não fez a opção por educar seu povo. Muito menos oferecer uma educação mais consistente, como fizeram os países do centro do capitalismo. Daí que no Brasil quando os trabalhadores em luta pautam a Educação essa não é levantada apenas como uma bandeira de direitos, mas e, sobretudo como instrumento de transformação a exemplo do que tem se configurado a luta pela política pública de Educação do Campo.

As lutas e relações que acontecem na construção da política pública de Educação do Campo, apresentam-se sob duas perspectivas: na sociedade atual, são sujeitos que se organizam e lutam por conquistas de direitos, e na segunda perspectiva como instrumento de transformação da sociedade e a emancipação humana, essa luta está vinculada a organizações, como é o caso do MST que tem esse objetivo como estratégia.

Por se tratar de interesses antagônicos, os trabalhadores, ao reivindicarem condições dignas de vida, afrontam os interesses da burguesia. Uma vez que tais direitos não são concedidos, esses interesses conflitantes podem ser perseguidos pela força. Dessa forma afirma Lessa:

A reprodução da sociedade ficaria inviabilizada se essa afirmação de forças degenerasse cotidianamente em luta aberta entre as classes, em guerra civil. Evitar que isso aconteça é a função social do Direito. Cabe ele regulamentar a vida por meio de leis que jamais ultrapassem a dominação de classe (...). O objetivo fundamental do direito será o de regulamentar a vida social de modo a que ela possa se reproduzir sobre a base da propriedade privada. (2008, p. 57).

Por isso a luta por direito é uma luta importante, mas limitada, pois circunscreve-se na sociedade do capital, ou como diz Iasi: 
(...) Em sua luta revolucionária, não basta o proletariado assumir-se enquanto classe (consciência em si), mas é necessário se assumir para além de si mesmo (consciência para si). Conceber-se não apenas como grupo particular com interesses próprios dentro da ordem capitalista, mas também se colocar diante da tarefa histórica da superação dessa ordem. (...) A verdadeira consciência de classe é fruto dessa dupla negação: num momento, o proletariado nega o capitalismo assumindo sua posição de classe, para depois negar-se a si próprio enquanto classe, assumindo a luta de toda sociedade por sua emancipação contra o capital (2011, p. 32).

A segunda perspectiva comporta a primeira, porém extrapola, pois se vincula a organizações que almejam a transformação da sociedade, podendo desta forma, direcionar-se na perspectiva da emancipação humana. Nesse caso, é o que podemos dizer da luta pela Educação do Campo. Como instrumento da classe ela ganha um caráter para além do direito, ela passa a ser instrumento de luta pela transformação da sociedade na medida em que contribui para elevar a consciência dos trabalhadores e contribuir com a organização dos mesmos. E é aqui que se localiza a principal contradição: fazer a luta pela educação de caráter emancipatório dentro de um Estado Burguês. Na definição de Antonio e Martins (2009, p.4).

O Estado burguês, como instituição, não é compreendido apenas como uma esfera administrativo-burocrática, mas como uma esfera pela qual se canalizam as relações políticas ou correlações de força relativas a um projeto de sociedade, permitindo compreender que as políticas sociais têm um caráter de classe, e estas colocadas no interior de certos valores democráticos. (...) A concepção de Estado moderno impõe-se como uma orientação importante para as lutas sociais, a qual se estabelece uma função necessária para colocar o Estado na condição de representante geral da sociedade, mascarando sua origem na luta de classes entre capital e trabalho.

Tomando o Estado sob uma perspectiva histórica, veremos que nem sempre ele existiu. Não por acaso, ele vai surgir com a divisão da sociedade em classes, como atesta Lênin: "Houve um tempo em que não havia Estado. Este ocorre no lugar e no momento em que surge a divisão da sociedade em classes, quando ocorrem os exploradores e os explorados" (LÊNIN, s/d, p. 5). $\mathrm{O}$ Estado não representa o interesse de todos, Lênin aponta que o Estado se constitui na luta de classe, no seio da sociedade cindida em classes sociais, portanto, ele não está acima dessa sociedade, mas é parte dela, marcado por suas contradições antagônicas, portanto inconciliáveis. Para o autor "o Estado surge precisamente onde, quando e na medida em que as contradições de classe objetivamente não podem ser conciliadas" (LÊNIN, 2007, p. 25).

Gramsci apud Neves e Sant'Anna (2005), sem abandonar a visão de Marx, Engels e Lenin sobre o Estado, incorpora outros elementos que a realidade foi apontando. Para ele, nas sociedades ocidentaisiii contemporâneas, em que o Estado não está mais restrito a nenhum poder absoluto, a obtenção do consenso se torna fundamental para que um projeto de sociedade se torne hegemônico, assumindo a direção político-cultural na perspectiva da conservação ou da 
transformação do conjunto da existência social.

Nas sociedades ocidentais, o Estado se amplia, adquirindo uma nova materialidade: complexificação da burocracia civil e militar da aparelhagem estatal ou do Estado em sentido estrito e crescente expansão qualitativa e quantitativa dos aparelhos privados de hegemonia da sociedade civil. (NEVES e SANT'ANNA, 2005, p.25).

Para Gramsci (ibidem), a crescente politização da sociedade civil, ao consubstanciá-la também em expressão coletiva, constituiu-a em uma dimensão superestrutural nova, à qual ele se referirá sistematicamente quando de suas análises acerca das modificações da estrutura e da dinâmica política das sociedades contemporâneas, denominadas por ele de "sociedade ocidentais" ou aquelas nas quais força e consentimento, em justa relação, garantem a dominação de classe.

Esta forma do Estado governar, estendendo seus braços à sociedade civil - através de espaços públicos não estatais, como comitês, fóruns, conferências - tem a intenção de criar o consenso na sociedade. Para Gramsci, o Estado e sociedade civil se distinguem apenas na função que cumprem, mas o que um faz incide sobre o outro, havendo assim uma imbricação entre as tarefas do Estado e da sociedade civil. Desta forma Gramsci não os separa. Para ele, Estado é igual a "sociedade política + sociedade civil, isto é, hegemonia couraçada na coerção" (idem).

O conceito de Estado Ampliadoiv, que Gramsci vai desenvolver no âmbito do marxismo, parte da preocupação por compreender como a sociedade burguesa organiza sua dominação e, portanto, como é possível enfrentá-la. Deste modo, o Estado passa a assumir cada vez mais um papel educador, redefinindo suas práticas, instaurando, por meio de uma pedagogia da hegemonia, uma relação entre aparelhagem estatal e sociedade civil na atualidade, com vista a afirmar o Projeto Neoliberal de sociabilidade (NEVES e SANT'ANNA, 2005, p.). Afirma Neves que a ampliação da democracia e o Estado educador têm uma relação direta.

O Estado educador, como elemento de cultura ativa, deve servir para determinar a vontade de construir, no invólucro da sociedade política, uma complexa e bem-articulada sociedade civil, em que o individuo particular se governe por si sem que, por isso, esse autogoverno entre em conflito com a sociedade política, tornando-se ao contrario, sua normal continuação, seu completo orgânico. (NEVES e SANT'ANNA 2005, p. 26 e 27)

Neves afirma ainda que, diferente das sociedades orientais, em que a pedagogia da hegemonia era exercida principalmente por meio de ações que tinham funções educativas regressivas e negativas (em especial por intermédio dos tribunais): 
Nas sociedades ocidentais, mais politicamente estruturadas, a pedagogia da hegemonia passa a se exercer mais sistematicamente por meio de ações com função educativa positiva, que se desenvolve primordialmente na sociedade civil, nos aparelhos de hegemonia política e cultural das classes dominantes, sendo para Gramsci, a escola o mais importante deles. (ibidem, p. 27).

Poulantzas de igual modo vai trazer a escola e a educação como uma instância de socialização e de construção de hegemonia. Para ele, a educação, como política social, é resultado das formas de orientação política da gestão do Estado capitalista.

Levando em consideração as realidades analisadas pelos autores acerca do Estado e os contextos históricos e abordagens que cada um faz do Estado, é possível afirma o caráter inconciliável das classes em um Estado capitalista. Independente de sua forma o Estado, persistirá sempre o núcleo que o faz continuar capitalista sem impedir que ele passe por importantes transformações ao longo da reprodução do capitalismo.

Tomando o caso brasileiro, teremos uma especificidade na constituição do Estado, dadas as condições históricas sob a qual ele se forjou. Essa condição foi de total subordinação sociopolítica e cultural à metrópole, reproduzindo nas instituições sociais brasileiras durante o período colonial valores e comportamentos que ainda se fazem presentes nas práticas políticas, na configuração e na atuação do Estado e, por conseguinte, na compreensão do que é público. Essa configuração constitui-se em uma cultura patrimonialista, onde o público é tomado pelo privado e confundido como tal, na qual a hegemonia familiar extrapola o domínio do lar e da fazenda. Para Araujo (2000), "não conseguem ainda hoje separar o público do privado, porque para a elite, o Estado é a continuação de suas propriedades" ( p.297).

David e Maciel (2010, p.2), estudando o Estado e a Revolução em Florestan Fernandes, dizem que:

O Estado burguês brasileiro constitui-se como uma autocracia, restringindo a sociedade civil e a Nação por ele reconhecidas aos estratos burgueses e seus movimentos políticos e sociais, excluindo politicamente a enorme massa popular, e interditando a ascensão dos trabalhadores, em particular, e das classes oprimidas, em geral, à condição de sujeito político.

Desta forma, o Estado brasileiro tem sua formação e desenvolvimento profundamente articulados a essas oligarquias. Daí não dá para esperar que este Estado implemente políticas que atentem contra os interesses da classe dominante. Para Florestan Fernandes isso se justifica pelo fato de as classes dominantes não poderem ceder terreno no campo da educação escolarizada sem arriscar-se a permitir que as classes trabalhadoras ganhem acesso a técnica que ameaçam de maneira crescente os que mandam arriscando transformar uma sociedade de analfabetos em públicos reivindicantes. 


\section{A CONTRIBUIÇÃO DO MST PARA UMA EDUCAÇÃO CONTRA HEGEMÔNICA}

Não dá para compreender em separado a luta pela terra e pela Educação do Campo. Há uma simbiose entre essas duas lutas: ao mesmo tempo em que o MST luta pela terra aponta a necessidade da luta pela educação, essa por sua vez vem contribuindo no seu salto qualitativo. A complexidade que a luta pela terra adquiriu na contemporaneidade colocou novos desafios aos movimentos sociais, fazendo-se necessário buscar novas formas de resistência. A própria estrutura das organizações se complexificou para dar conta dos novos desafios. Essa complexificação provocou a necessidade da preparação dos trabalhadores e de suas organizações, fazendo com que entrasse em pauta a luta pelo acesso ao conhecimento. Esses deixaram de lado a condição de isolamento, e nas ruas passaram a ser instituidores de políticas.

Os Movimentos Sociais, no final da década de 1980, motivados pela retomada das lutas sociais no Brasil, com forte influência da Teologia da Libertação e da Educação Popular, passam a reescrever outra história. Rompendo o silenciamento imposto pela ditadura militar, passaram a lutar pelos direitos civis, políticos e sociais.

Tomando como exemplo o Movimento Sem Terra, veremos que além da terra esse Movimento passa a pautar também a luta pela educação. No primeiro momento, que corresponde à sua primeira fase - que vai de 1978 a 1983 - a luta era pelo acesso à escola para atender os filhos e filhas dos acampados e assentados. A partir da conquista dessas escolas, as famílias perceberam, ao observar a condução da escola, que não bastava ter garantido o acesso, mas que a escola tinha que corresponder ao projeto de sociedade e de ser humano que o MST vislumbrava como estratégia política, na sua luta por Reforma Agrária e pelo Socialismo.

A compreensão do MST é de que a educação dos trabalhadores Sem Terra não pode ficar a cargo do Estado, e passa a enfrentar essa luta na perspectiva de que o Estado não pode ser o educador do povo, deve apenas, garantir o financiamento e as condições como gestor dos recursos públicos, como advertiu Marx apud. Manacorda, 2010, p.102 "O ensino pode ser estatal sem estar sob o controle do governo". Porém na sociedade capitalista o Estado representa os interesses da classe hegemônica, logo, a luta pela educação pública ocorre imbuída de tensões e contradições.

O MST passa a disputar a escola, desde a interferência na contratação de professores e, principalmente, na forma e conteúdo da educação. Esse posicionamento inaugura de forma articulada a luta por uma política pública de Educação desde os sujeitos. O inaugurar aqui diz respeito a uma luta histórica da Educação Popular, de seus fundamentos poderem fazer parte do sistema público de educação.

A experiência educacional e escolar do MST é compreendida como ferramenta de luta, de fortalecimento da organização social e política e de instrumento para a superação dessa sociedade de classe. Desta forma, insere os sujeitos neste movimento da história, vivendo experiências de formação humana, da organização social, que são próprias da luta de classe. Vedramini, (2007, p. 133) observa que: 
Os movimentos sociais do campo, entre eles o MST, têm pressionado não só pela Reforma Agrária e por uma política agrícola que viabilize a pequena produção no campo, mas também por uma educação e escolarização para uma população historicamente alijada das políticas públicas. Ainda que o Movimento esteja envolvido diretamente nas lutas por uma educação do campo, seu projeto de formação vai mais além, ao desenvolver ações políticas que em si são educativas e ao direcionar a formação não só para o aspecto técnico e escolar, mas essencialmente político.

Dessa forma, a concepção de educação do MST é de que ela é um dos processos de formação humana, que se desenvolve em um processo de relação com outras pessoas, baseada em valores humanistas e socialistas (MST, 1999, p. 6). O Movimento Sem Terra, quando assume a discussão da educação, se pergunta: que escola queremos? E como fazer a escola que queremos? Esse debate se dá porque a política de educação e de escola que se apresentava nas áreas conquistadas não era de superação da atual sociedade, pelo contrário, era de manutenção do sistema vigente. Assim, a contradição instaurada é: queremos escola, mas esta que aí está não nos serve. Então o desafio é: como construir uma educação que não reproduza a atual sociedade e que sirva de sustentação à sociedade que queremos construir?

Por isso, mesmo que a educação que o MST se propõe a construir seja pensada a partir de um movimento social em particular, esta não se esgota nela mesma, pois seu princípio é de uma educação da classe trabalhadora. Senão vejamos:

Nos seus Princípios Filosóficos, o MST concebe uma educação pautada na "transformação social, um processo pedagógico que se assume como político, vinculado organicamente com os processos sociais que visam à transformação da sociedade, cujos principais pilares sejam a justiça social, a radicalidade democrática e os valores humanistas e socialistas", (MST, 2005, p.161). Educação como ferramenta para emancipação humana. Daí que, mesmo no particular de um movimento específico ela se torna universal, pois traz em sua concepção princípios para além do MST, para além do campo, traz princípios para outra sociedade. Uma educação pensada desde um movimento social, mas que não se encerra nele mesmo é universalizante, pois seus princípios são universalizantes, tem na sua concepção filosófica o trabalho e o ser humano. Três princípios da educação do MST apontam nessa direção:

a) Princípio do Trabalho, o trabalho na concepção marxista, como criação, como formação humana. Compreendendo que as pessoas se humanizam ou se desumanizam, se educam ou se deseducam através do trabalho e das relações sociais que estabelecem entre si no processo de produção material de sua existência. Uma educação que coloca o ser humano no centro do seu projeto educativo, uma educação Unitária do trabalho; b) Educação Onilateral como forma de reintegrar as diversas esferas da vida humana, que o capitalismo separou, que leve ao pleno desenvolvimento do ser humano, rompendo com a escola dualista; c) Educação com Valores Humanistas e Socialistas que reconstrua os valores de uma nova ordem social, radicalmente democrática, verdadeiramente humana (MST, 2005, p.161). 
Para Frigotto (2010), o MST em seu projeto societário e educacional "engendra o gérmen mais avançado da luta contra hegemônica hoje no Brasil, não só para a educação do campo, mas para a classe trabalhadora no seu conjunto" (p. 20). E continua Frigotto:

Na realidade brasileira de hoje, encontramos experiências que lutam nesta direção. A mais orgânica e ampla e, por isso, a mais combatida pela classe burguesa brasileira, é a do projeto societário e educativo do Movimento dos Sem Terra. Por articular a educação a mudanças radicais num projeto societário, é ali que vislumbramos os elementos mais avançados de uma educação que busca ir além do capital e, portanto, é contra-hegemônica ao projeto social e educacional de capitalismo dependente do Brasil. (FRIGOTTO, 2010, p.34)

É com a compreensão de que embora a escola seja pensada para manutenção da ordem, ela é necessária para contribuir com a elevação da consciência dos trabalhadores buscando superar o senso comum e elevando a uma consciência filosófica. Nesse sentido, entende o MST, que a educação é um dos meios pelo qual os trabalhadores possam compreender e disputar o projeto de sociedade. Ao mesmo tempo em que o Movimento projeta o direito à educação, a educação no Movimento serve para avançar o universo cultural dos Sem Terra, ajudando a dar respostas de desenvolvimento econômico e político nas áreas conquistadas. E só com aglutinação das forças é que poderá alterar essa correlação desfavorável de se construir uma educação para além do direito, que seja de luta. Desta forma, ao falar da Educação do MST, fala-se de uma concepção de educação fundamentada em princípios filosóficos e pedagógicos, que extrapola a sala de aula, mas também pensa a partir dela.

É nessa compreensão que os movimentos têm pautado a luta pela educação do campo como necessária para um projeto de reforma agrária. E faz parte da pauta da Educação do Campo políticas que vão desde a alfabetização de jovens e adultos, assim como políticas que garantam a elevação de escolaridade desses sujeitos. Não são descartados os programas como medida de superar as distorções impostas pela falta de atendimento da política na idade regular, mas esses devem ser combinados com uma política estruturante, que abarque desde as questões pedagógicas até as físicas, como construção de escolas e melhorias nas estradas e transportes intra-campo. Esse investimento é necessário para que não precise mais se valer de programas para corrigir distorções da política ou da falta dela. Entre essas políticas estruturantes estão o investimento no atendimento da educação básica nas próprias comunidades, investimento em infraestrutura necessária para uma educação de qualidade e valorização dos educadores do campo.

\section{AS ATUAIS CONFIGURAÇÕES DAS RELAÇÕES ESTADO E MOVIMENTO DE LUTA NO CAMPO: EM QUESTÃO A REFORMA AGRÁRIA E A EDUCAÇÃO DO CAMPO}

Tomando o período em análise, 2003 a 2013, que correspondem os governos Luiz Inácio Lula da Silva e Dilma Rousseff, inicialmente, esperava-se que se alterasse a correlação 
de forças a favor da classe trabalhadora, no que diz respeito ao atendimento às bandeiras históricas dos trabalhadores, principalmente da reforma agrária e da educação.

Passada uma década, observa-se que as expectativas depositadas na primeira eleição de Lula da Silva, tanto no sentido de atender a essas reivindicações históricas dos trabalhadores como no sentido de apresentar iniciativas mais ousadas por parte do governo para implementálas, deram lugar a um governo que "persegue uma política de conciliação" (CEZIMBRA, SANTOS e MARTINS, 2012, p. 16). O que significa dizer que os governos petistas, ao invés de fazerem a ruptura necessária com os grupos que historicamente governaram o país, fizeram a opção pela governabilidade, buscou alianças que vão da esquerda até a direita. Essas alianças comprometeram o projeto da classe trabalhadora, que viu frustrado o atendimento as suas demandas.

O modelo macroeconômico não mudou com a mudança de governo, manteve sua lógica centrada nos ganhos especulativos ligados ao capital financeiro. $\mathrm{O}$ que significa dizer que $\mathrm{o}$ capital seguiu seu curso com o apoio do governo, que por sua vez manteve-se prestativo às necessidades do capital. Esse modelo em curso adotado pelo governo Lula da Silva, e assumido pelo governo Dilma Rousseff, vem sendo denominado pelos movimentos sociais e por alguns cientistas políticos como neodesenvolvimentista, no qual o Estado investe, constrói e entrega para exploração do capital privado. Esse modelo caracteriza-se pelo tripé:

a) Estado investidor: se manifesta no programa de Aceleração do Crescimento (PAC), com um conjunto de grandes obras de infraestrutura para alavancar o desenvolvimento do país; b) Estado Financiador: impulsiona a constituição de fortes grupos econômicos, de grandes multinacionais brasileiras com capacidade competitiva no mercado internacional, através do BNDES (ajuda na fusão entre as empresas. como é o caso da Perdigão-Sadia); c) Estado Social: diminuidor da pobreza e miséria, como Programa bolsa-família, política compensatória e não emancipatória (propaganda do projeto "Brasil Sem Miséria", sem nenhuma reforma estruturante). (CEZIMBRA, SANTOS e MARTINS, 2012, p. 18).

Motta (s/d p. 9), na análise que faz a respeito do novo-desenvolvimentismov brasileiro, identifica que ele começa no segundo mandato do governo de Lula da Silva em que os anúncios sobre crescimento econômico passam a ser associado ao de desenvolvimento social, justificados pelo que seria a implementação de um modelo alternativo ao neoliberalismo. Motta analisa ainda:

Que a proposta "Novo-desenvolvimentista" vai ao encontro da proposta de desenvolvimento disseminada pelos principais organismos multilaterais - conciliar Estado, mercado e sociedade civil; exercer um Estado eficiente, governado por gerentes "autônomos e responsáveis perante a sociedade" nas intervenções aos males do capitalismo, como defende Bresser-Pereira (2004); promover políticas de redução da pobreza da ampla massa de trabalhadores; criar parcerias público- 
privadas, com empresas, bancos e organizações empresariais e da sociedade civil para colaborar nos encaminhamentos das políticas de enfrentamento da "questão social" e na eficácia das instituições estatais, entre outras "ações articuladas". (ibidem)

Frigotto (2010, p. 5) na análise que faz sobre o governo Lula em comparação ao Governo de Fernando Henrique Cardoso destaca o que para ele são as chaves para compreender as diferenças entre as políticas assumidas por tais governos. Para ele, o que se mantém como continuidade em relação ao passado é a opção por conciliar uma minoria prepotente a uma maioria desvalida, mediante o combate à desigualdade dentro da ordem de uma sociedade capitalista onde sua classe dominante é das mais violentas e despóticas do mundo. De forma análoga ao que Florestan Fernandes fez em relação à luta pela democracia, podemos dizer da esperança depositada no governo petista.

Não foi um erro confiar na democracia e lutar pela revolução nacional. $\mathrm{O}$ erro foi outro - o de supor que se poderiam atingir esses fins percorrendo a estrada real dos privilégios na companhia dos privilegiados. Não há reforma que concilie uma minoria prepotente a uma maioria desvalida. (...) A causa principal consiste em ficar rente à maioria e às suas necessidades econômicas, culturais e políticas: pôr o povo no centro da história, como mola mestra da Nação. (FERNANDES apud. FRIGOTTO, 2010, p. 4).

Para o MST, este é um momento muito delicado, pois ao completar trinta anos tem visto sua principal bandeira de luta ser paulatinamente descartada da agenda de um governo que se acreditava comprometido com a luta pela Reforma Agrária e que se rende à força que hegemoniza o campo brasileiro hoje - o agronegócio. Ao contrario, do que se esperava o governo Lula e Dilma abandona essa nobre tarefa de fazer a reforma agrária e:

Manteve [mantém] em alta consideração o agronegócio, ao mesmo tempo em que diz ser possível manter uma política de apoio à agricultura familiar e à reforma agrária. Na prática apregoa a convivência harmoniosa entre dois modelos de agricultura para o país onde, em geral, os interesses são contraditórios. E o agronegócio, vinculado ao setor patronal-multinacional, é quem dá o ritmo e usa escandalosamente o Estado para garantir seus interesses. (CEZIMBRA, SANTOS e MARTINS, 2012, p. 18)

A opção de governar pela conciliação levou e tem levado os governos petistas não só a adiar novamente a tarefa de fazer a reforma agrária no Brasil, como a implementar formas de domesticar a luta pela terra. Para tal intento criou espaços de construção de consenso, de forma a tirar a reforma agrária de evidência e deixar o capital/agronegócio agir livremente. Os 
conflitos que garantiam a visibilidade da luta continuam a acontecer, só que agora de forma oculta, uma vez que não são mais mostrados pelos meios de comunicação social e os despejos são negociados através de espaços criados para tal finalidade, conforme atesta Mafort e Amorim (2012, p.72):

O Estado, para evitar conflitos e nos tirar da mídia e da comunicação direta com a sociedade, através das nossas ações de resistência contra a violência do latifúndio e dos órgãos de repressão do próprio Estado, criou as ouvidorias Agrárias, Promotoria Agrária, policia especializada que em alguns estados criaram varas agrárias. E construíram em comum acordo com diversas organizações da sociedade civil e entidades de direitos humanos um processo de mediações e resoluções de conflitos agrários. Ou seja, encontraram uma forma de nos comprometer a cumprir os decretos de reintegração de posse de forma negociada pacificamente, sem expor publicamente o conflito agrário. (ibidem).

Os trabalhadores, esperançosos com a eleição de um governo dito de esquerda, que poderia implementar políticas eficientes e universalizantes, foram levados a disputar seus projetos em espaços institucionalizados como fóruns e comitês. Esses espaços, ao mesmo tempo em que criam no imaginário social a idéia de participação efetiva na política, legitimam políticas de cunho compensatório para os trabalhadores. Com isso, analisa Frigotto (2010, p. 13), o Estado, em vez de alargar o fundo público na perspectiva do atendimento a políticas públicas de caráter universal, fragmenta as ações em políticas focais que amenizam os efeitos, sem alterar substancialmente as suas determinações.

Há um reconhecimento de que os governos petistas Lula e Dilma, ampliaram as políticas sociais, porém de caráter assistencialista. No caso da educação, por exemplo, esses governos ampliaram os espaços de acesso sem, contudo, disputar o projeto pedagógico na perspectiva na perspectiva da classe trabalhadora. Frigotto (2010) analisando a educação brasileira na primeira década do século XXI diz que:

Ao não disputar um projeto societário antagônico à modernização e ao capitalismo dependente e, portanto, à expansão do capital em nossa sociedade, centrando-se num projeto desenvolvimentista com foco no consumo e, ao estabelecer políticas e programas para a grande massa de desvalidos, harmonizando-as com os interesses da classe dominante (a minoria prepotente), o governo também não disputou um projeto educacional antagônico, no conteúdo, no método e na forma. (FRIGOTTO, p.9).

A Educação do campo, frente a essa conjuntura, não ficou imune, pois ela é fruto das contradições do sistema agrário e agrícola e da problemática da educação rural brasileira. Analisando o que ocorreu, e vem ocorrendo, com a Educação do Campo, é possível acrescentar que o governo, não só, não disputou a concepção, o conteúdo, o método e a forma, como tem 
buscando aniquilar experiências que vêm se configurando como contrahegemônicas. Com a correlação de força desfavorável aos trabalhadores, a radicalidade da luta pela política pública de Educação do Campo foi sendo conduzida para espaços institucionalizados, o que tem levado ao arrefecimento da luta

\section{EDUCAÇÃO DO CAMPO: TRAJETÓRIA HISTÓRICA}

A discussão da Educação do Campo surge no cenário brasileiro porque a luta pela terra estava na pauta política. Essa caminhada tem como marco o I Encontro Nacional dos Educadores/as da Reforma Agrária - I ENERA, em 1997. Esse encontro provoca o debate por parte dos organizadores e apoiadores sobre a problemática pela qual estava passando a educação do campo com a política de fechamento das escolas, adotada pelo governo federal. Esse debate aponta para necessidade de articulação com outras organizações da sociedade para enfrentar essa problemática. Desta forma aponta para a realização de uma Conferência Nacional de Educação do Campo que veio a ocorrer em Luziânia, no estado de Goiás, em julho do ano seguinte. Essa Conferência possibilitou articular/aproximar nos estados todas as organizações que estavam desenvolvendo trabalhos de Educação no Campo.

Após a primeira Conferência, as organizações sociais mantiveram-se mobilizadas através de uma Articulação Nacional, para dar prosseguimento à luta pela formulação e operacionalização da política pública de Educação do Campo. Essa Articulação vai manter-se articulada até a segunda Conferência. Em novembro de 2002, por ocasião da eleição do presidente Luiz Inácio Lula da Silva, com as esperanças renovadas de que poderia avançar na construção de uma política pública de Educação do Campo, é realizado em novembro o Seminário Nacional de Educação do Campo em Brasília, com o objetivo de formular uma pauta de demandas para o novo presidente.

A partir de 2004, com a realização da segunda e última conferência de Educação do Campo, há um recuo por parte das organizações imposta pela ofensiva do capital, o que levou à dissolução dessa Articulação. A partir de 2006 o MEC passa a realizar seminários estaduais de Educação do Campo em parcerias com as secretarias estaduais de educação que tinha como desdobramento a criação de fóruns ou comitês de Educação do Campo. Essa conjuntura vai acarretar em um deslocamento de lugar da Educação do Campo, dos Movimentos Sociais para as universidades, Fóruns e Comitês. O que até 2004 era uma articulação, na qual, a luta pela Educação do Campo estava vinculada diretamente às organizações de luta pela terra, torna-se um movimento autônomo - Movimento da Educação do Campo. Agora o debate da Educação do Campo passa a se dar muito mais em espaços institucionalizados e fora das lutas mais amplas do campo e da classe. Molina (2010) corrobora com essa analise quando diz:

Percebe-se um recuo, uma diminuição da pressão por parte destes sujeitos coletivos [Movimentos Sociais], para a conquista das políticas públicas de Educação do Campo. Mobilizações nacionais coletivas, envolvendo uma grande diversidade de organizações, tiveram seu último grande ato no processo de preparação e realização da $I I$ Conferência Nacional Por uma Educação do Campo, em 2004. De lá para cá, as ações e reivindicações têm sido feitas de forma mais 
desarticuladas, isoladas, não havendo aglutinação entre diferentes movimentos, e muito menos, entre movimentos e organizações parceiras, como universidades e outros aliados do Movimento da Educação do Campo. (p. 109 e 110).

A caminhada por uma Política Pública de Educação do Campo completa 16 anos. Dessa luta algumas conquistas podem ser contabilizadas, embora elas tenham ficado bem aquém do que se reivindica. Pode-se relacionar a criação do Programa Nacional de Educação na Reforma Agrária - PRONERA; as Diretrizes Operacionais para a Educação Básica das Escolas do Campo Resolução CNE/CEB $\mathrm{N}^{\circ}$ 1/2002; A Licenciatura em Educação do Campo (PROCAMPO); o Saberes da Terra; as Diretrizes Complementares Resolução CNE/CEB N ${ }^{\circ}$ 2/2008; a criação dos Observatórios de Educação do Campo; e o Decreto Presidencial de Decreto $\mathrm{n}^{\circ} 7.352$, de 4 de novembro de 2010.

É inegável que a temática da Educação do Campo cresceu de forma vigorosa. Ganhou espaço nas universidades, com a criação de observatórios de Educação do Campo; foi incorporada nas agendas de pesquisas das universidades; várias universidades têm promovido seminários de Educação do Campo; em boa parte dos estados e municípios foram criadas Coordenadorias de Educação do Campo nas Secretarias de Educação. Mas todo esse avanço, em sua grande parte, está longe das práticas políticas dos Movimentos Sociais. Em alguns casos isolam deliberadamente os Movimentos, não os incluindo nos debates ou nas formulações das políticas.

\section{ANÁLISE DESSE PERCURSO}

Tomado numa perspectiva de totalidade, os avanços e limites que a Educação do Campo teve nesses dezesseis anos não se explica por ela mesma, se não, como resultado de uma correlação de forças que se enfrentam na luta por terra e por educação no cenário brasileiro. Se tomarmos a Educação do Campo como uma particularidade da política educacional dos governos Lula/Dilma, encontraremos a universalidade do que representou, e representa, no campo educacional, a postura desses dois governos. Longe de ser um instrumento para avançar a política educacional brasileira disputando a forma, o método e o conteúdo da educação, apostando na superação de uma histórica negação à educação para as camadas sociais menos favorecidas, essas políticas têm gerado o fortalecimento dos setores hegemônicos, perpetuando a histórica educação dual no Brasil com ênfase da instrumentalização para empregabilidade.

Podemos tomar como exemplo o programa Projovem Saberes da Terravi., como expressão de uma política de Educação do Campo dos governos Lula e Dilma. Criado em 2005 para atender a elevação de escolaridades de jovens e adultos, nesse programa podemos acompanhar o tratamento dispensado à Educação do Campo nesses governos. O programa Saberes da Terra foi uma conquista dos movimentos de luta social do campo que influenciou, sobretudo no seu projeto político pedagógico. Dois anos mais tarde em 2008, o programa se reconfigurou no PROJOVEM Campo - Saberes da Terra como versão campo do Projovem que teve mais três versões, o urbano, adolescente e trabalhador. Nessa reconfiguração houve mudanças substanciais, entre elas, a faixa etária atendida pelo programa, que passou de 15 a 29 anos prioritariamente, para 18 a 29 anos exclusivamente, deixando de fora a parcela da 
população adulta analfabeta.

Outro ponto que sofreu alteração foi a carga horária. A primeira versão (2005) previa uma carga horária de 3.200 horas/aula, sendo $2.400 \mathrm{~h} / \mathrm{a}$ no tempo escola e $800 \mathrm{~h} / \mathrm{a}$ no tempo comunidade. Na edição de 2008, a carga horária foi reduzida para 2.400 h/a, sendo 1800 h/a no tempo escola e $600 \mathrm{~h} / \mathrm{a}$ no tempo comunidade. Este fator foi uma nítida expressão do afastamento do programa de sua concepção original, com o rebaixamento no tempo de formação da juventude. Esse programa não rompe com a histórica discriminação entre campo e cidade, por parte das políticas públicas, revelada na diferença dos valores das bolsas pagas aos estudantes. Enquanto o valor pago ao Projovem Urbano era de $\mathrm{R} \$ 100,00$ reais por mês, o Projovem Campo era de 50,00 reais. Para disfarçar essa discriminação, foi anunciado como $\mathrm{R} \$$ 100,00 reais a cada dois meses. E sem nenhuma consideração aos sujeitos que estavam conduzindo a implementação da política, retiram o edital 2010.

Após a suspensão do edital 2010, não se voltou a falar em seu retorno. Ele não aparece como ação do PRONACAMPO, não apareceu com Resolução específica. Pelos indicativos que aparecem na Resolução No48/2012 apontam que ele foi metamorfoseado nesta resolução. O que implica uma derrota na política de Educação do Campo, haja vista, que ele estava sendo apontado pelas organizações do campo como uma política que respondia às exigências filosóficas da Educação do campo além do que há uma redução da carga horária para 1600 horas o que aponta para uma desqualificação da formação da juventude, priorizando a instrumentalização para empregabilidade.

Avaliando o período anterior à eleição do governo petista, em que corresponde o massacre de Eldorado dos Carajás (1996), veremos que a luta pela Educação do Campo sofre das mesmas investidas do capital no campo, imposta aos movimentos de luta pela terra. A luta pela terra neste período ganha maior visibilidade o que gera maior apoio da sociedade. A marcha nacional ocorrida em 1997 é expressão desse apoio, em que na chegada a Brasília, somou-se mais de cem mil pessoas.

Na Educação do Campo, vai ser tomado como marco dessa caminhada o I ENERA, realizado em 1997. A segunda iniciativa também gestada neste encontro foi o Programa Nacional de Educação na Reforma Agrária- PRONERA, a primeira conferencia de Educação do Campo e elaboradas as Diretrizes Operacionais para Escolas da Educação Básica do Campo, aprovadas em 2002.

Em 2002 é eleito Luiz Inácio Lula da Silva, presidente do Brasil. Abrem-se aqui novas correlações de força. Esperava-se que essa conjuntura fosse alterada a favor da classe trabalhadora. Passada uma década que corresponde aos governos petistas Lula e Dilma, classifico em três momentos a construção da política pública de Educação do campo. O primeiro momento nomeado de "Esperança acesa", numa alusão ao slogan do governo Lula, "A esperança venceu o medo"; o segundo, "Aceno para a esquerda e virada para direita", percebese refletida nos encaminhamentos da política a posição do governo Lula para com a Educação do Campo; e o terceiro momento, "Ceder para incorporar" - já no governo Dilma -, Diante da disputa de projeto para o campo mais acirrado e a aposta do governo no agronegócio, mais clara, combinada com o total abandono da reforma agrária e com o avanço do agronegócio sobre vastos territórios nas terras dos camponeses, comunidades quilombolas, indígenas e outras comunidades tradicionais, o governo começa a tomar para si o comando da Educação do Campo. 


\section{ESPERANÇA ACESA -2003 A 2007}

Tomado como marco a posse do novo governo - Lula. Imbuídos de esperança, se aposta que ele fará avançar as lutas e conquistas que os trabalhadores do campo vinham obtendo à custa de muito sangue, a exemplo do massacre de Eldourado dos Carajás. O MST na ocasião faz uma avaliaçãovii de que com a posse do Lula, o governo deixaria de ser seu principal inimigo, voltando-se novamente para o latifundiário. Nessa nova conjuntura, com o governo em disputa os latifundiários passaram a se apoiar em outras esferas do Estado para tencioná-lo e impedir que os trabalhadores avançassem em suas conquistas. Atuaram principalmente através do judiciário e do parlamento - legislativo. Em uma permanente ofensiva para criminalizar os movimentos sociais, apoiaram-se também no Tribunal de Conta da União - TCU, na Controladoria Geral da União (CGU) e nos meios de comunicação social. Em dezembro de 2003 instauram a Comissão Parlamentar Mista de Inquérito - CPMI da Terra.

A CPMI da Terra que durou dois anos não consegui provar nada, tentaram então transformar a luta pela terra em "ação terrorista" como tentativa de impor derrotas aos movimentos, pressionando o governo Lula, para que se distanciasse de tais organizações. As investidas contra os movimentos não cessaram. Passaram a agir em questões pontuais como nas ofensivas contra o PRONERA, buscando criar um clima de pânico e criminalizar quem coordenava as ações nas universidades.

\section{ACENO PARA ESQUERDA E VIRADA À DIREITA - 2008 A 2010}

Avaliamos que ao mesmo tempo em que o governo acenava com regulamentação da política de Educação do Campo, como a Resolução CNE/CEB N ${ }^{\circ}$ 2/2008viii, e o decreto presidencial de 2010ix, ele vai tomando medidas que retiram os movimentos dessas políticas.

Em 2009, a elite agrária através de suas representações no parlamento volta novamente a investir na ofensiva judicial contra as organizações dos trabalhadores do campo. Instaura-se a CPI da Reforma Agrária, em dezembro desse mesmo ano. Essa CPI da Reforma Agrária buscava novamente ligações entre os recursos de investimento nas áreas de reforma agrária e os desvios desses recursos para financiar as ocupações de terra.

Uma ação orquestrada e articulada de ataques aos movimentos partiu de todos os setores da burguesia. Por um lado a mídia implementou a "tática do silêncio", não mais divulgando as mobilizações e ações de luta realizadas pelos movimentos, principalmente pelo MST, que tinha as ações mais articuladas e incisivas contra o latifúndio e o agronegócio, na tentativa de passar uma idéia de recuo e enfraquecimento. Por outro lado o poder judiciário implementa uma ofensiva nos tribunais, tentando criminalizar os movimentos.

O governo acenou positivamente à classe dominante, retirando do Brasil Alfabetizado todas as organizações não governamentais, inclusive as que representavam os Movimentos Sociais. De igual modo, paralisaram o Programa Nacional de Educação na Reforma Agrária, impondo medo aos seus coordenadores, criminalizando-os, parando cursos em andamento, impondo a retirada dos movimentos sociais de tal parceria, suspende o edital 2010 do Projovem Campo - Saberes da Terra. Criaram, dessa forma, uma blindagem nas políticas de Educação do Campo que vinham sendo gestadas com ampla participação dos Movimentos Sociais Populares 
do Campo.

\section{CEDER PARA INCORPORAR - 2010 AOS DIAS ATUAIS}

O governo começa a tomar para si o comando da Educação do Campo. O que para os Movimentos era avaliado como política fragmentada e descontínua, para a elite agrária era uma ameaça, pois como ação fragmentada passava despercebida do controle do Estado. Foram mais de 13 anos de construção de uma política em que os Movimentos estavam sendo sujeitos de um novo jeito de fazer educação, influenciando na forma, no conteúdo e no método, a exemplo do Programa Nacional de Educação na Reforma Agrária - PRONERA. Esse programa é considerado uma política pública construída de forma ascendente, pois nasceu das reivindicações dos Movimentos Sociais de luta pela terra, num contexto de acirramentos dos conflitos agrários. Ele foi criado dentro do Ministério do Desenvolvimento Agrário e conduzido pelo Instituto Nacional de Colonização e Reforma Agrária - INCRA com ampla participação dos movimentos sociais e sindicais do campo, sujeitos historicamente impulsionadores das políticas de Reforma Agrária no Brasil. Esse programa tem como objetivo geral ampliar a escolarização formal dos trabalhadores rurais, compreendendo a educação como condição fundamental para o desenvolvimento dos assentamentos.

O decreto presidencial de 2010 institucionaliza o PRONERA que deixa de ser um programa e passa a se constituir enquanto uma política pública de Estado. Essa ação representa uma conquista dos movimentos, mas inverte sua lógica de funcionamento. Na sua proposta de origem, eram os movimentos sociais que apresentavam as demandas da formação para as instituições formadoras, e em parceria, coordenavam os cursos. Com o novo decreto, as demandas passam a ser apresentada pelas instituições formadoras via edital e não mais pelos movimentos sociais.

Em 2010 é criado o Fórum Nacional de Educação do Campo - O FONEC, que tem como característica a articulação dos sujeitos sociais coletivos, pautados pelo princípio da autonomia em relação ao Estado, sendo integrado pelos movimentos sociais e sindicais do campo, pelos Fóruns Estaduais de Educação do Campo, pelas Redes, Universidades, e Institutos Federais. E tem como objetivo o exercício da análise crítica constante, severa e independente acerca de políticas públicas de Educação do Campo; bem como a correspondente ação política com vistas à implantação, à consolidação e, mesmo, à elaboração de proposições de políticas públicas de Educação do Campo.

Atendendo às reivindicações dos Movimentos Sociais Populares do Campo e ao mesmo tempo cedendo às pressões da elite agrária o governo cria um programa de Educação do Campo - o PRONACAMPO. Apresentado como um conjunto de ações articuladas de uma política de Educação do Campo fruto de mobilizações de entidades e organizações de trabalhadores, iniciadas, nestes termos, no final da década de 1990, o referido programa buscou ser uma política que contentasse as duas forças em conflito.

O PRONACAMPO representa a síntese dessa conjuntura de luta de classe: se por um lado ele é resultado da luta dos trabalhadores por uma política pública de Educação do Campo, por outro, ele vem se configurando como a incorporação e ajustamento da demanda social ao projeto hegemônico, como traduzido no documento final do Seminário do FONEC (2012, p. 17) 
"o Pronacampo não é linearmente contra os trabalhadores, mas também não representa a vitória do pólo do trabalho na definição da política". Se não, como explicar a presença da senadora Kátia Abreu, representante do agronegócio em seu lançamento e a entrega do ensino profissionalizante quase que totalmente ao SENARX?

A análise que o FONEC (idem) faz desse contexto histórico permite identificar no Pronacampo, em sua lógica geral de formulação, e especialmente no quesito da formação técnico-profissional, a expressão da atual hegemonia do capital no campo, contendo elementos da pressão das lutas dos trabalhadores. O problema estrutural, que entendemos ser fruto dessa hegemonia, é que não fica apontada na política a efetiva construção de um sistema público de educação escolar de qualidade para todos os trabalhadores do campo. Sua ênfase está em garantir elementos de política pública que permitam avançar na preparação da mão-de-obra para o agronegócio ou diminuir os focos de conflito com os camponeses, suas organizações de classe.

\section{CONSIDERAÇÕES FINAIS}

Considerando os limites e possibilidades do processo de construção de políticas públicas de Educação do Campo no marco do Estado burguês o presente artigo analisou as reivindicações dos trabalhadores do campo nos governos petista de Luiz Inácio Lula da Silva e Dilma Rousseff. Buscamos entender as relações entre Estado, Educação e Movimentos Sociais Populares, nos valendo de Antonio e Martins para dizer sobre as conclusões a que chegamos dessas relações. Segundo os autores:

A relação entre Estado e movimentos sociais populares do campo é uma expressão das contradições que estamos focalizando. Nesse contexto, apreende-se a origem contestadora das condições educacionais para a população do campo, emergidas das contradições históricas sobre a função do Estado capitalista. Portanto, a questão do Estado e das políticas sociais pode ser abordada na perspectiva das relações contraditórias imperativas desse Estado, como também, a partir das relações de força presentes na produção dessas políticas. (ANTONIO e MARTINS, 2009, p.45).

Dessas relações o que constatamos é que, o Estado, enquanto instrumento de classe, vai sempre agir para a manutenção da ordem, com algumas concessões a depender da correlação de força, da classe ou da fração de classe que estiver no poder. É o que podemos constatar dos governos petistas Lula e Dilma, que no primeiro momentos esperava-se que sendo governos que representava as forças sociais fossem atender as bandeiras de luta dos trabalhadores. Vimos essa esperança acessa, de construir um projeto contra hegemônico, paulatinamente ir perdendo força e nas poucas concessões que esses governos concederam o fizeram buscando incorporá-los ao sistema.

Marx dizia que "os homens fazem a sua própria história, mas não a fazem segundo sua livre vontade, em circunstancias escolhidas por eles próprios". (MARX, 2008, p. 207). O que significa dizer que para cada momento/período histórico a luta política da classe tem determinadas tarefas. Nessa conjuntura, em que há um descenso das lutas, reflete também na constituição das políticas. Dessa forma é que percebemos o recuo que tem ocorrido com a 
Educação do Campo. Esse recuo é a expressão de uma conjuntura que se inicia com a CPMI da Reforma Agrária tem imposto derrotas as bandeiras históricas dos trabalhadores, sobretudo a bandeira da Reforma Agrária. Como expressão dessa conjuntura observa-se que desde 2004 há um deslocamento da política de Educação do Campo dos movimentos sociais, que foram até então, os sujeitos do processo, para os espaços institucionais com a criação dos comitês e Fóruns de Educação do Campo e espaços acadêmicos

Constatamos também que, a situação da educação dos povos do campo, longe de ser solucionada por uma política pública eficiente, tem sido tratada por programas ineficientes e fragmentados. Esses programas têm se constituído cada vez mais em alternativas para educação do campo, desobrigando o Estado de ofertar uma política consistente de educação como forma de não gerar mais jovens analfabetos e que garanta a dignidade aos povos do campo. $\mathrm{O}$ PRONACAMPO é a expressão mais articulada dessa política que poderia vir a ser uma resposta consistente à Educação do Campo, porém é apenas mais um programa e expressa a intenção do capital para a formação dos trabalhadores do campo, ensino técnico, aligeirado, referenciado a empregabilidade.

A tarefa posta aos movimentos, e em particular ao MST, nessa conjuntura em que a correlação de forças está desfavorável aos trabalhadores, é de continuar resistindo e buscando dar uma formação política aos trabalhadores, de forma a possibilitar a elevação da consciência e compreensão desse momento histórico para não se deixar cooptar e nem se deixar derrotar.

Como a meta perseguida é a transformação da base material dessa sociedade, continuar-se-á tencionando o Estado para garantir a educação aos trabalhadores. Condição essa, necessária para elevação da consciência a uma dimensão filosófica. Dessa forma a luta pela Educação do Campo, no marco das organizações que a criaram, continuará pressionando o Estado pela sua efetivação, sem, contudo deixar o comando em suas mãos. Esse caberá às organizações utilizando-a como instrumento de luta na perspectiva da emancipação humana.

\section{NOTAS}

i Militante e coordenadora do setor de Educação do Movimento Sem Terra no estado de Pernambuco.

ii Este artigo baseou-se na pesquisa monográfica de conclusão do curso Trabalho, Educação e Movimentos Sociais da Escola Politécnica de Saúde Joaquim Venâncio e teve como tema Projovem Campo - Saberes da Terra: análise das reivindicações dos trabalhadores do campo e das propostas dos Governos de Luiz Inácio Lula da Silva e Dilma Rousseff.

iii Ver a respeito em NEVES, Lúcia Maria Wanderley (org). A Nova Pedagogia da Hegemonia: estratégia do capital para educar o consenso. São Paulo: Xamâ, 2005, p. 20-39.

iv Ver a respeito em NEVES, Lúcia Maria Wanderley (org). A Nova Pedagogia da Hegemonia: estratégia do capital para educar o consenso. São Paulo: Xamâ, 2005, p. 20-39.

v Segundo Motta (s/d, p.9) essa denominação teve como inspiração um artigo de BresserPereira publicado na Folha de São Paulo em 19 de setembro de 2004 com o mesmo título. Neste 
artigo Bresser-Pereira relaciona a idéia de "novo-desenvolvimentismo" com uma estratégia nacional de desenvolvimento, que deve conter os seguintes elementos estratégicos: aumento da abertura de conta comercial, de forma negociada e recíproca; um novo papel do Estado, com planejamento mais estratégico; estabilidade econômica, incluindo estabilidade de preços, equilíbrio na balança de pagamento e busca do pleno emprego; uma "nova" política econômica que vise a "inverter a equação de juros elevados e câmbio apreciado"; negação da estratégia de crescimento com poupança externa, visando à alternativa de desenvolvimento com recursos próprios.

vi A versão original do Programa foi constituída a partir de uma ação interministerial dirigida inicialmente pela Coordenação Geral de Educação do Campo (CGEC), vinculada à Secretaria de Educação Continuada, Alfabetização e Diversidade (SECAD/ MEC). Tinha como objetivos, elevar a escolaridade e proporcionar qualificação profissional inicial de agricultores familiares; Estimular o desenvolvimento sustentável como possibilidade de vida, trabalho e constituição de sujeitos cidadãos do campo; Fortalecer o desenvolvimento de propostas pedagógicas e metodologias adequadas à modalidade de EJA no campo; Realizar formação continuada em metodologias e princípios políticos pedagógicos voltados às especificidades do campo para os educadores envolvidos no Programa; Publicar e fornecer materiais pedagógicos apropriados ao desenvolvimento da proposta pedagógica; Estimular a permanência dos jovens na escola por meio da concessão de auxílio financeiro.(MEC 2005, p. 9).

vii Reunião da Direção Nacional em janeiro de 2003, em Caruaru- Pernambuco, ano em que toma posse o governo Lula em seu primeiro mandato. Nessa Reunião o MST define sua postura em relação ao governo Lula.

viii Resolução $\mathrm{N}^{\circ}$ 02, de 28 de abril de 2008, Diretrizes Complementares, Normas e Princípios para o Desenvolvimento de Políticas Públicas de Atendimento à Educação Básica do Campo.

ix O Decreto Presidencial n. 7.352 de 04 de novembro de 2010 dispõe sobre a Política Nacional de Educação do Campo e sobre o Programa Nacional de Educação na Reforma Agrária (PRONERA), instituindo metas e ações específicas para a Educação do Campo. Estas ações preconizam a melhoria do ensino nas redes de ensino existentes no campo, bem como a formação de professores, a produção de material didático e acesso e recuperação da infraestrutura e qualidade da educação do campo em todas as etapas e Modalidades.

x Serviço de Aprendizagem Rural - SENAR, entidade formadora da Confederação da Agricultura e Pecuária do Brasil - CNA.

\section{REFERENCIAS BIBLIOGRÁFICAS}

ANTONIO, Clécio A.; MARTINS, Fernando José. Estado, Educação e Movimentos sociais do campo: luta social pela educação do campo no Brasil. X Congresso Luso-AfroBrasileiro de Ciências Sociais. Braga, Portugal, 2009.

ARAUJO, Tânia Bacelar de. Ensaios sobre o desenvolvimento Brasileiro. Rio de Janeiro, Ed. Revan, 2000.

BOGO, Ademar. Linguagem em Prosa e Verso: uma mediação para a formação da 
consciência. Monografia apresentada ao Colegiado de Letras do Departamento de Educação/ Campus X/ UNEB como requisito parcial para a obtenção do título de licenciado (a) em Letras Vernáculas, aprovada pela banca examinadora. Teixeira de Freitas, 2011.

CEZIMBRA, Elemar de; SANTOS, Marina dos e MARTINS, Horácio. A Natureza do Estado Burguês e dos Governos e sua Relação com as Políticas Agrária e Agrícola. Subsídio para debate de temas estruturais da Sociedade brasileira e os desafios para uma reforma agrária popular. Caderno de Debats N 1. SãoPaulo, 2012.

FONEC. MANIFESTO À SOCIEDADE BRASILEIRA. Brasília, 2012.

FRIGOTTO, Gaudêncio .Os Circuitos da História e o Balanço da Educação no Brasil na Primeira Década do Século XXI. Conferencia de Abertura da XXXIII Reunião da Associação Nacional de Pesquisa e Pós-graduação em Educação (ANPED). Caxambu, MG. 2010.

HOLANDA, Sérgio Buarque. Raízes do Brasil. 26a Ed. São Paulo. Editora Companhia das Letras, 1995.

IASI, Mauro Luiz. Ensaios sobre consciência e emancipação. São Paulo: Expressão Popular, 2011.

LENIN, Vladimir Ilitch. O Estado e a Revolução: O que ensina o Marxismo sobre o Estado e o papel do Proletariado na Revolução. Tradução e revista por Aristides Lobo. 1 ed. São Paulo: Expressão Popular, 2007.

LESSA, Sérgio; TONET, Ivo. Introdução à Filosofia de Marx. 1ª Ed. São Paulo: Ed. Expressão Popular, 2008.

MACIEL, David. Florestan Fernandes e a questão do transformismo na transição democrática brasileira. Anais do IV Simpósio Lutas Sociais na América Latina ISSN: 21779503. GEPAL, Londrina, 2010.

MANACORCA, Mario Alighiero. Marx e a Pedagogia Moderna. Tradução Newton de Oliveira Campinas, SP: Ed. Alínea, 2010. $2^{\mathrm{a}}$ ed.

MAFORT, Kelli; AMORIM, Jaime. A tática: Como obter conquistas e acomular Forças na atual conjuntura da $\mathbf{r}$ eforma agrária. Subsídio para debate de temas estruturais da Sociedade brasileira e os desafios para uma reforma agrária popular. Caderno de Debats $\mathrm{N}^{\circ}$ 1. SãoPaulo, 2012.

MARX, Karl Heinrich; ENGELS Friedrich., A Sagarda Família ou a crítica da Crítica crítica: Contra Bruno Bauer e Consortes.. Tradução e Notas Marcelo Backesm. São Paulo. Ed. Boitempo, 2009.

MEC/SECAD. (2005). Programa Saberes

da Terra. Projeto Politico-Pedagógico. Brasília. DF.Brasil.

MEC/FNDE. (2012). Resolução No 48 de 02 de outubro de 2012. Brasília. DF.Brasil.

MÉSZÁROS, IstvánA educação para além do capital. São Paulo: Boitempo, 2005. 
MOLINA, Mônica Castagna. Desafios teóricos e Práticos na Execução das Políticas Públisa de Educação do Campo. In: Educação do Campo: Reflexões e Perspectivas. Orgs. MUNARIM, Antônio; BELTRAME, Sônia; FRANZONI, Soraya Conde; PEIXER, Zilma Isabel. Florianópolis: Ed.: Insular, 2010.

MOTTA, Vânia Cardoso da. Capital Social e o Novo-desenvolvimentismo Brasileiro: mudança no pensamento sobre desenvolvimento - UERJ, Rio de Janeiro (s/d)

MST - Dosie MST e a Escola:1990 - 2001. Ed. 2005.

NEVES, Lúcia Maria Wanderley (org). A Nova Pedagogia da Hegemonia: estratégia do capital para educar o consenso. São Paulo: Xamâ, 2005.

POULANTZAS, Nicos. As lutas Politicas: O Estado, Condensação de uma Relação de Forças. In POULANTZAS, Nicos. O Estado, o Poder, o Socialismo. São Paulo: Paz e Terra, 2000.

SOARES, Eliane Veras. Educação e Democracia na Trajetória de Florestan Fernandes. In. Cadernos de Estudos da ENFF: O Legado de Florestan Fernandes. Escola Nacional Florestan Fernandes. São Paulo, 2009.

TAFFAREL, Celi Nelza Zulke. Teoria Pedagógica Marxista e Educação Escolar no Contesto da Luta de Classe Contemporânea . Texto apresentado no VI Encontro de Educação, Marxismo e Emancipação Humana- Irecê, 2011.

VENDRAMINI, Célia Regina. Educação e Trabalho: Reflexões em torno dos Movimentos Sociais do Campo. Cad. Cedes, Campinas, vol. 27, n. 72, p. 121-135, maio/ago. 2007. 